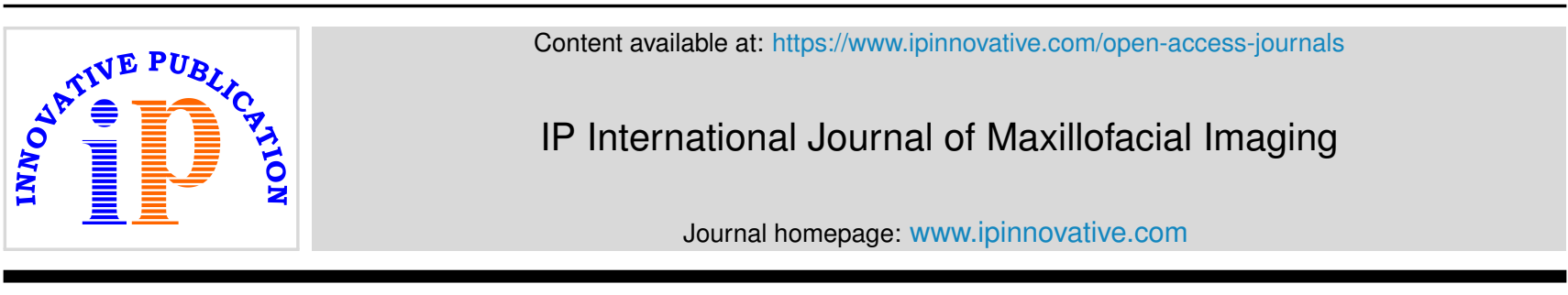

Original Research Article

\title{
Evaluation of tooth coronal index bicervical diameter in mesiodistal direction \& modified kvaals method for age and gender determination using digital panoramic radiographs: A retrospective study
}

\author{
Jyoti Sukhwani $^{1, *}$, Abhijeet Deoghare ${ }^{1}$, Chinar Fating ${ }^{1}$, Satyendra Kumar Jha1, \\ Rohit Biranjan ${ }^{1}$ \\ ${ }^{1}$ Dept. of Oral Medicine \& Radiology, Chhattisgarh Dental College, Rajnandgaon, Chhattisgarh, India
}

\section{A R T I C L E I N F O}

\section{Article history:}

Received 03-07-2020

Accepted 04-08-2020

Available online 07-10-2020

\section{Keywords:}

Age estimation

Bicervical diameter

Panoramic radiograph

Pulp cavity height

Pulp/tooth ratio

Tooth coronal index

\begin{abstract}
A B S T R A C T
Background: The aim of this study was to evaluate tooth coronal index, bicervical diameter in mesiodistal direction \& modified kvaal's method of age estimation for age and gender determination.

Materials and Methods: The digital panoramic radiographs of 200 subjects of aged 20-60 years were selected for the study. Tooth Coronal Index(TCI), height of the crown i.e Coronal Height $(\mathrm{CH})$ and the height of the coronal pulp cavity i.e Coronal pulp cavity height $(\mathrm{CPCH})$ of mandibular first molars was measured in millimeter(mm). Then TCI was calculated and calculated age was compared with chronological age. For pulp/tooth ratio, the measurements of Pulp Chamber Height (PCH) and Crown Root Trunk Height (CRTH) were performed on the mandibular first molar the pulp chamber crown root trunk height ratios (PCTHR) of selected tooth were calculated. Also the bicervical diameter in mesiodistal direction was measured. The measurements were performed on these JEPG images by using Digimizer 5.3 Software. The acquired data were subjected to Pearson correlation test, unpaired t test and Analysis of variance (ANOVA) analysis.

Results: Results suggested that statistically significant differences were observed between chronological and calculated age with TCI for right mandibular molar, $\mathrm{CPCH}$ and Mesiodistal dimension where as $\mathrm{CH}$ shows negative correlation with chronological age.
\end{abstract}

(C) 2020 Published by Innovative Publication. This is an open access article under the CC BY-NC license (https://creativecommons.org/licenses/by-nc/4.0/)

\section{Introduction}

Human teeth have proved to be the most reliable marker in forensic science. With the advancement of radiology in forensic science, radiographic images can be utilized for age estimation with the advantage of being non invasive. ${ }^{1}$ Tooth coronal pulp index (TCI) based on reduction in the size of dental pulp with advancing age as a result of secondary dentin deposition. ${ }^{2}$ TCI will be calculated by $\mathrm{TCI}=\mathrm{CPCH} \times 100 / \mathrm{CH}$ where $\mathrm{CPCH}$ is coronal pulp cavity height and $\mathrm{CH}$ is coronal height. ${ }^{3}$ Kvaal et al. used deposition of secondary dentin by measuring pulp radiolucency and correlated it to age. ${ }^{1}$ Parameters measured were tooth length, pulp length and the root length from CEJ

\footnotetext{
* Corresponding author.

E-mail address: jsukhwani26@gmail.com (J. Sukhwani).
}

and calculated by specific regression formula. ${ }^{4}$ dimorphism in permanent tooth size, favouring males over females. ${ }^{5}$ The bicervical diameter in mesiodistal direction of posterior teeth is larger for males than females. ${ }^{6}$ The present study was done to assess the accuracy of age estimation from TCI, Modified kvaal's method and bicervical diameter in mesiodistal direction by radiographic analysis.

\section{Materials and Methods}

A total of 277 digital panoramic radiographs were retrospectively screened, out of which 200 were selected for the study based on the inclusion and exclusion criteria. 


\subsection{Inclusion criteria}

Digital panoramic radiographs of dentate subjects aged between $20-60$ years.

Good quality images showing complete morphology of the tooth.

\subsection{Exclusion criteria}

Digital panoramic radiographs with distorted images, carious / grossly decayed or periapical pathology, prosthesis, severely attrited or fractured teeth, rotated or malaligned teeth and teeth with any developmental anomalies were excluded from the study.

\subsection{Radiographic measurements}

The study was carried out in the Department of Oral Medicine \& Radiology in Chhattisgarh Dental College \& Research Institute, Rajnandgaon. All 200 panoramic radiographs were subjected to radiographic measurements. They were exported as JPEG image format by using SIDEXIS, Digital Image software (SIRONA). The measurements were performed on JEPG images by using Digimizer 5.3 Software.

\subsection{Measurement of tooth coronal index (TCI)}

In the present study, for selected teeth (right mandibular molar) a straight line (cervical line) was drawn from the cemento enamel junction, which is the division between anatomical crown and root. Coronal height $(\mathrm{CH})$ was measured vertically straight from the cervical line to the tip of the highest cusp according to Moss et al. ${ }^{7}$ Coronal pulp cavity height $(\mathrm{CPCH})$ was measured vertically from the cervical line to the tip of the highest pulp horn according to Ikeda et al. ${ }^{8}$ The measurements provided the TCI of each tooth, which was then calculated as follows. $\mathrm{TCI}=\mathrm{CPCH}$ $\times 100 / \mathrm{CH}$. (Figure 5)

\subsection{Age assessment by pulp /tooth ratio of mandibular first molar by modified kvaal's method}

The measurements were performed by method proposed by Mathew et al. For Right mandibular first Molar, Crown Root Trunk Height (CRTH) was calculated which is the distance between the central fossa and the highest point on root furcation. Pulp chamber Height (PCH) was calculated which is the distance between the roof and floor of the pulp of the pulp chamber in the same axis. Resultant Pulp Chamber Crown Root Trunk Height Ratio (PCTHR) was calculated as: PCTHR= PCH/CRTH. (Figure 6)

\subsection{Bicervical diameter in mesiodistal direction}

Bicervical diameter in mesiodistal direction was measured by a vertical line drawn from contact point in mesial and distal aspect of lower right mandibular molar. Distance measured between these two vertical lines was the bicervical diameter in mesiodistal direction (recorded in $\mathrm{mm}$ ).(Figure 7)

\section{Results}

Digital panaromic radiographs of 200 subjects between age 20-60 years were retrospectively analyzed of which 119 were males and 81 females [Table 1]. By using TCI there was statistically significant positive correlation between chronological age and TCI of mandibular first molar $(r=0.977)$ and correlation coefficient $(0.23)$. By using unpaired $t$ test there was highly significant difference $(\mathrm{P}=0.001)$ observed between mean chronological age and mean estimated age for mandibular first molar for males $(32.9916 \pm 9.05491)$ and for females $(28.8395 \pm 5.66007)$. No significant correlation was derived between PCTHR with gender $(\mathrm{P}=0.24)$. Positive correlation was observed between the PCTHR and chronological age for mandibular first molar, statistically significant difference was observed

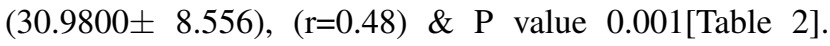
Regression analysis on the test sample produced the following linear regression equation.

In present study sample regression equation; $y=47.866 x$ +17.996 where $\mathrm{x}$ is dependent variable (age) \& $\mathrm{y}$ is independent variable (PCTHR). The $\mathrm{R}^{2}$ value for regression equation is 0.23 . No significant difference was found between the actual age and calculated age $(\mathrm{P}=0.853)$. [Table 3]. Mean absolute error was estimated by applying equation on the test sample and was found to be 7.51 years. In present study, age estimates in $80.5 \%$ was within the Mean absolute error, $< \pm 10$ years i.e. acceptable error limit in Forensic Age Estimation. Bicervical diameter in mesio distal direction showed statistically highly significant difference $(\mathrm{p} \leq 0.001)$ between male and female subjects. Bicervical diameter shows positive correlation with chronological age $(\mathrm{P}$ value $=0.043)$.

\section{Discussion}

Tooth is considered as a reliable body part for forensic age estimation since environment has minimal influence on it. Age estimation by radiographic evaluation of secondary dentin deposition is an established noninvasive procedure for adults. ${ }^{9}$ Gustafon was the first to introduce secondary dentin measurement method for age estimation. ${ }^{10}$ "Secondary dentin" is the calcified nontubular substance deposited by the pulp on the walls of the pulp chamber and root canal and it continues throughout the life. As regular secondary dentin is laid down on the pulpal surface of the primary dentin, the pulpal cavity decreases in size with age. ${ }^{3}$ It has been reported that secondary dentin apposition is not uniform all over the pulpal cavity i.e. in case of molars, it is more over the 


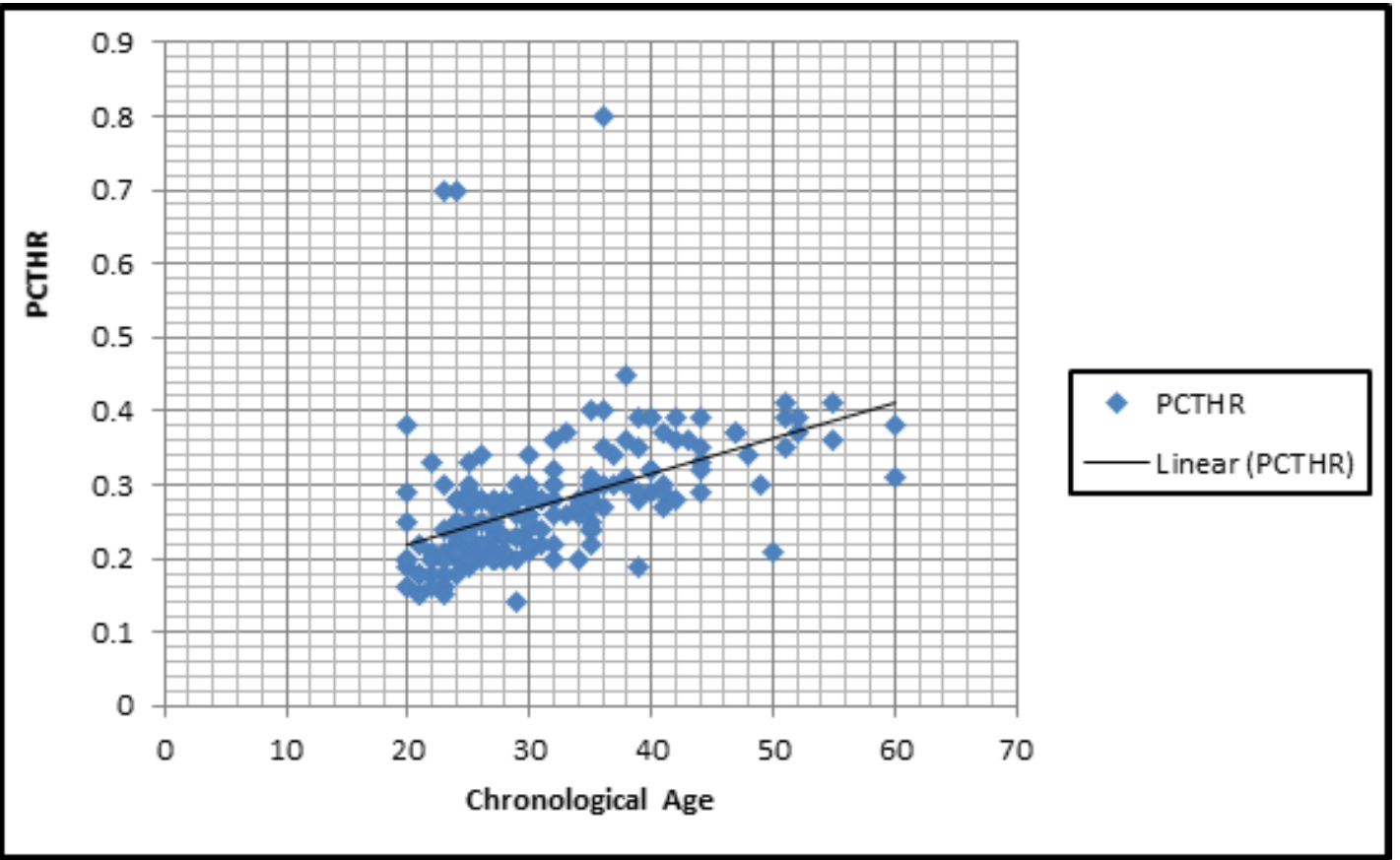

Fig. 1: Scattered plot showing regression line correlation between crown root trunk ratio when compared to subject's chronological age

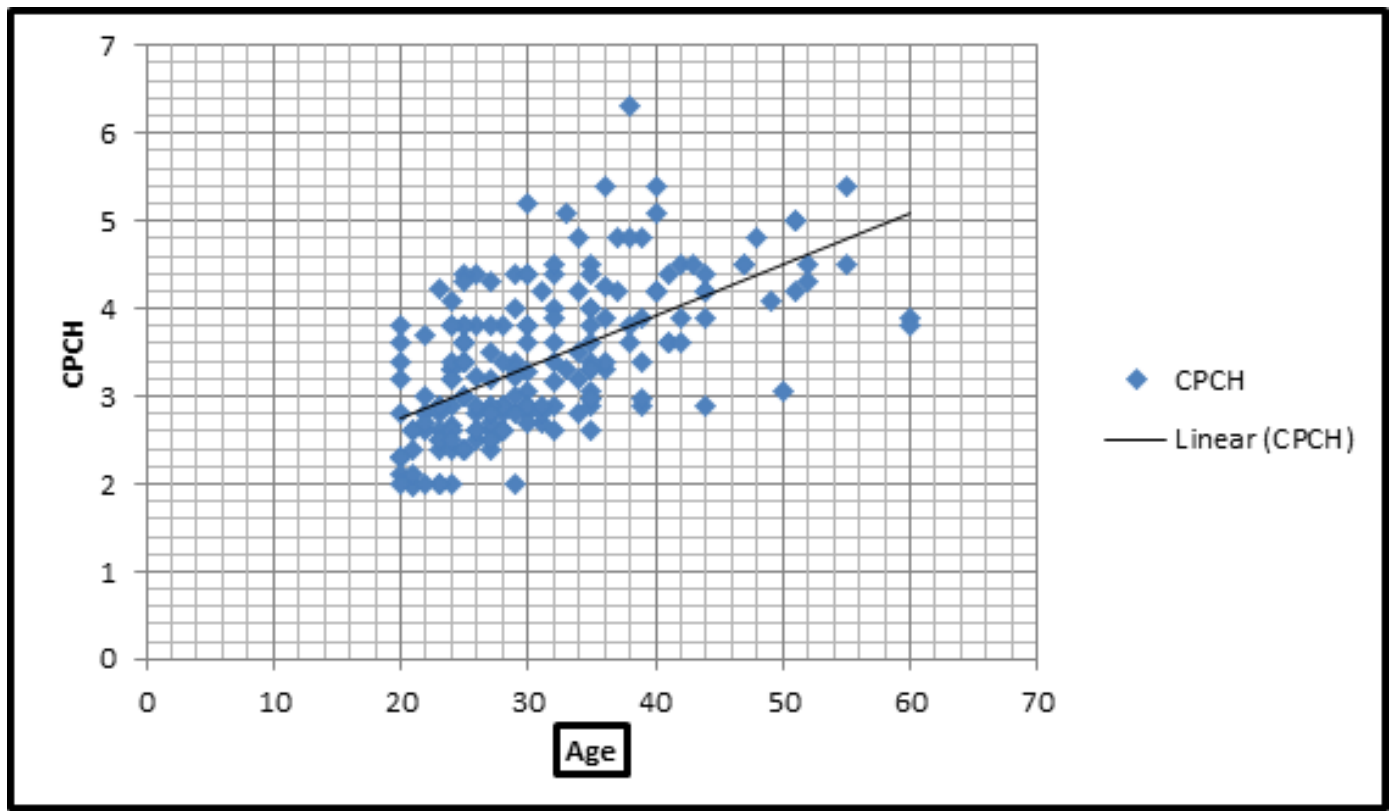

Fig. 2: Scattered plot showing regression line correlation between crown pulp chamber height with chronological age 


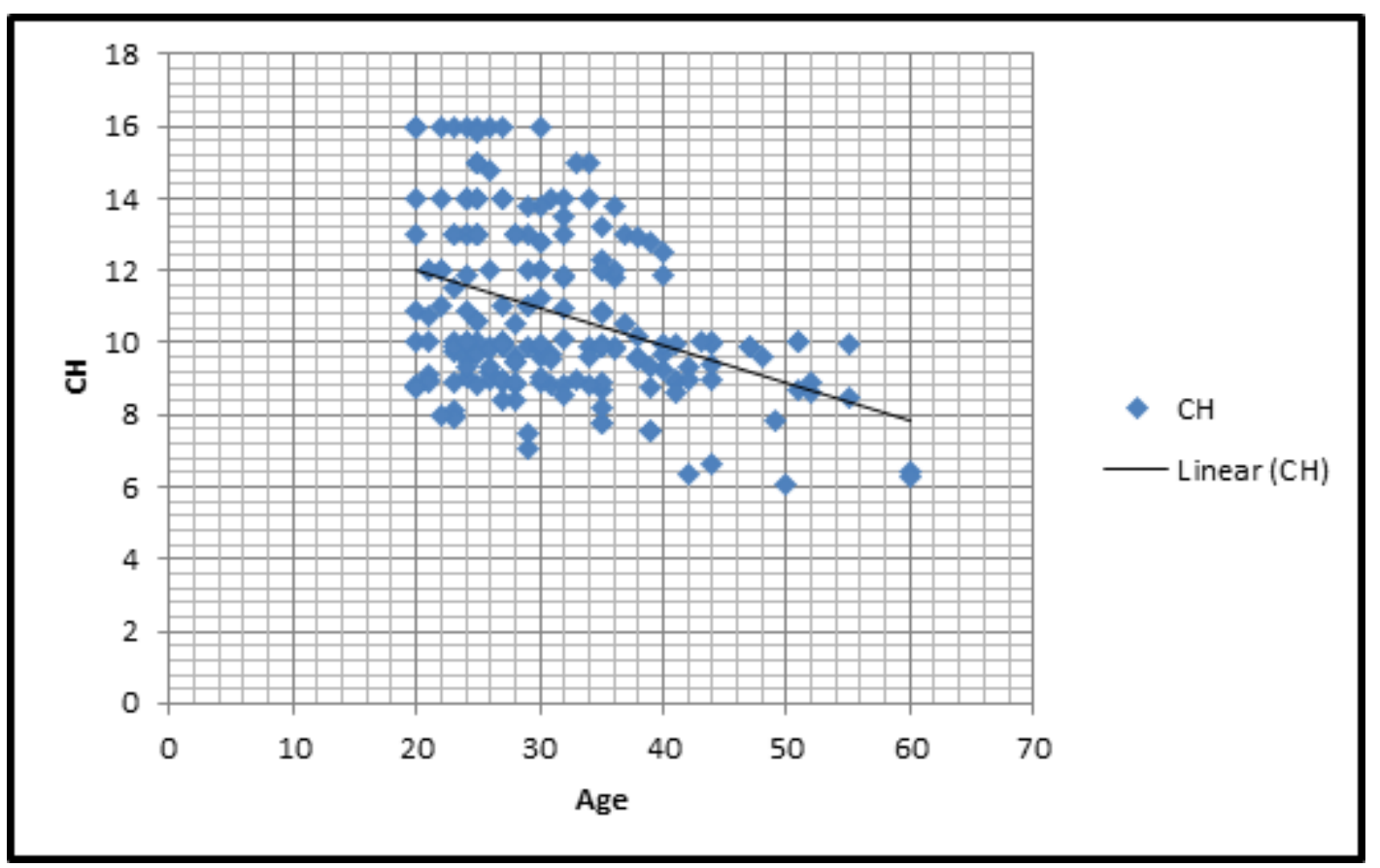

Fig. 3: Scattered plot showing regression line correlation between crown height and chronological age

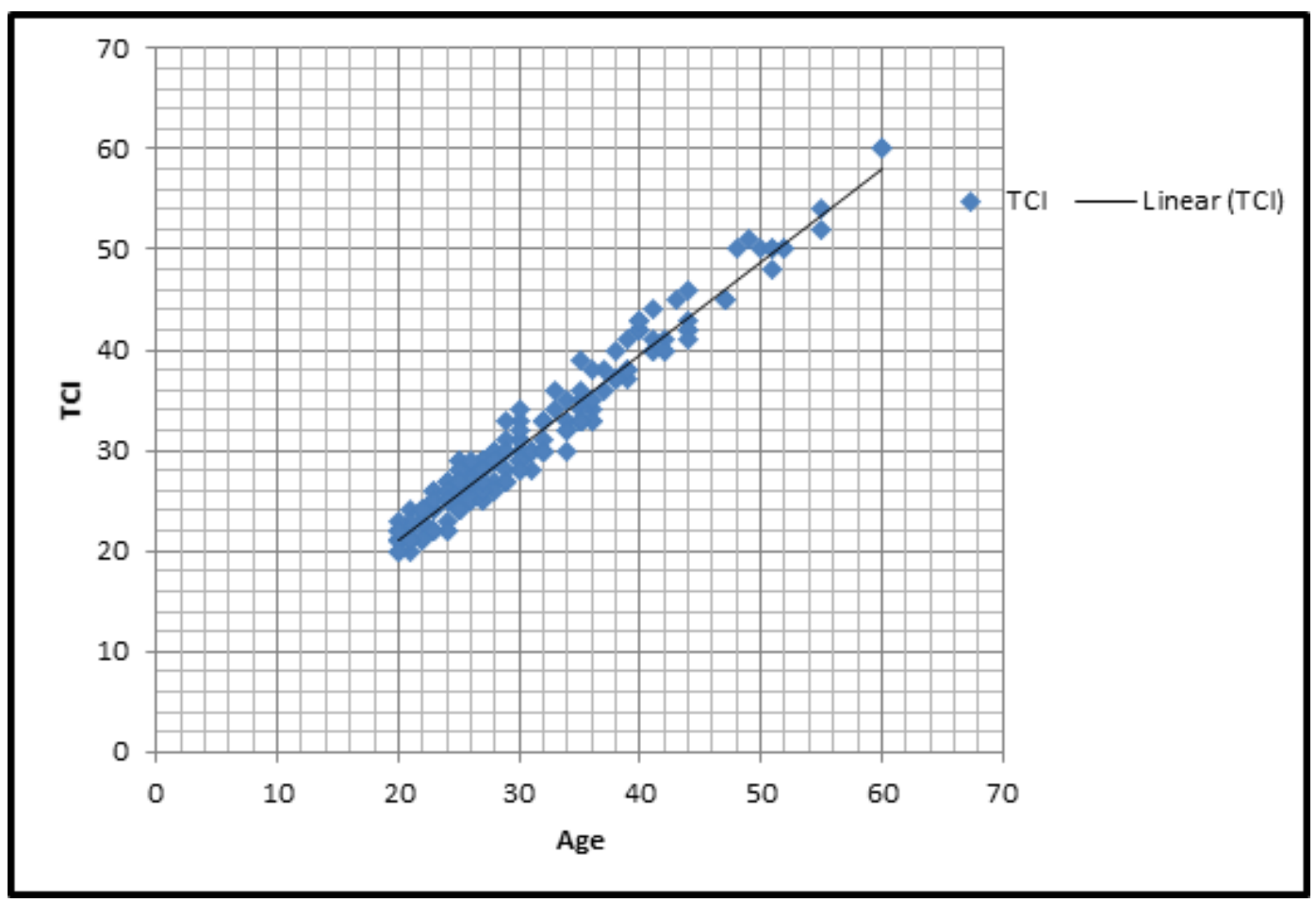

Fig. 4: Scattered plot showing regression line correlation between tooth coronal index with chronological age 
Table 1: Distribution of study subjects according to age categories \& gender $(\mathrm{N}=200)$

\begin{tabular}{llccc}
\hline & & Gender & Total & \\
& & Male & Female & 105 \\
& $20-29$ & 55 & 50 & 63 \\
Age Category & $30-39$ & 38 & 25 & 22 \\
& $40-49$ & 16 & 6 & 8 \\
Total & $50-59$ & 8 & 0 & 2 \\
\hline
\end{tabular}

Table 2: Correlation between chronological age \& PCTHR

\begin{tabular}{ccccc}
\hline & Mean & Std. Deviation & Pearson Correlation & P value \\
Age & 30.9800 & 8.55603 & 0.48 & $0.001 *$ \\
\hline
\end{tabular}

$\mathrm{P}$ value estimated using Pearson Correlation test, $*$ indicates statisticallysignificant $\mathrm{p}$ value

$P$ value is considered to be significant when $<0.05$ at $95 \%$ Confidence Interval

Table 3: Mean difference between actual age \& estimated age

\begin{tabular}{ccccc}
\hline & $\begin{array}{c}\text { Mean Chronological } \\
\text { Age }\end{array}$ & Mean Estimated Age & Mean Difference & P value \\
Age & 31.10 & 31.00 & 0.10 & 0.853 \\
\hline
\end{tabular}

Table 4: Comparison of MD, CH, CPCH, TCI, RTH \& PCTHR with respect to gender

\begin{tabular}{|c|c|c|c|c|c|c|}
\hline \multirow{2}{*}{ Gender } & \multirow{2}{*}{ No of samples } & \multicolumn{5}{|c|}{$\operatorname{Mean} \pm$ SD } \\
\hline & & $\mathrm{CPCH}$ & $\mathrm{CH}$ & TCI & PCTHR & MD \\
\hline Male & 119 & $3.49 \pm 0.8$ & $10.59 \pm 2.42$ & $32.99 \pm 9.05$ & $0.277 \pm 0.07$ & $11.98 \pm 1.33$ \\
\hline Female & 81 & $3.25 \pm 0.8$ & $11.19 \pm 2.24$ & $28.83 \pm 5.66$ & $0.26 \pm 0.09$ & $10.20 \pm 1.16$ \\
\hline $\mathrm{T}$ & & 2.069 & 1.77 & 3.66 & 1.053 & 9.73 \\
\hline P Value & & $0.040 *$ & 0.077 & $0.001 *$ & 0.294 & $0.001 *$ \\
\hline
\end{tabular}

$\mathrm{P}<0.05$-Significant. The present study sample MD, CPCH \& TCI show significant correlation with respect to gender where as CH and PCTHR were found to be non significant with respect to gender.

Table 5: Correlation of chronological age with TCI, CPCH, CH \& Mesio distal dimension

\begin{tabular}{llcc}
\hline & r (Correlation Coefficient) & P value & $0.001^{*}$ \\
Chronological Age & TCI & 0.977 & $0.001^{*}$ \\
& CPCH & 0.584 & $0.001^{*}$ \\
& CH & -0.394 & $0.043^{*}$ \\
\hline
\end{tabular}

TCI, $\mathrm{CPCH}$ and bicervical diameter in mesio distal direction showed positive correlation with age whereas $\mathrm{CH}$ show negative correlation with age

roof and floor, thus reducing the height rather than width of the pulpal chamber. ${ }^{11}$ Various studies have been done for age estimation using measurements of anterior teeth. But in elderly anterior teeth are often lost making age estimation difficult. ${ }^{12}$ In kvaal's method six anterior teeth (three maxillary and three mandibular teeth) were taken in to consideration and length and width measurements of teeth and dental pulp cavities were carried out. It was not possible to study the maxillary teeth due to the fact that digital radiographic images did not meet quality criteria because of overlap of adjacent tissues and lack of sharpness of the images. The following ratios were calculated :pulp/root length (P), pulp/tooth length(R), and pulp/root width at three levels(A,B and C) were also complicated. ${ }^{13}$ Bossman et al. in 2005 applied the technique of kvaal on digital orthopantomograms and obtained age estimation comparable to those based on original technique found no significant differences between chronological age and estimated age when all six teeth or all three mandibular teeth were included. ${ }^{14}$ Drusini et al in 1997 measured the highest point on the pulp chamber and the cervical line of posterior teeth to estimate age. But superimposition of adjacent pulp horns and thin cemento enamel junctions had lead to inaccuracy of measurements. ${ }^{15}$ Paewinsky et al. revealed that width ratios at different root levels showed significant correlations with chronological age. Although this investigation consisted the application of the method of Kvaal et al. On panoramic radiographs, results were 


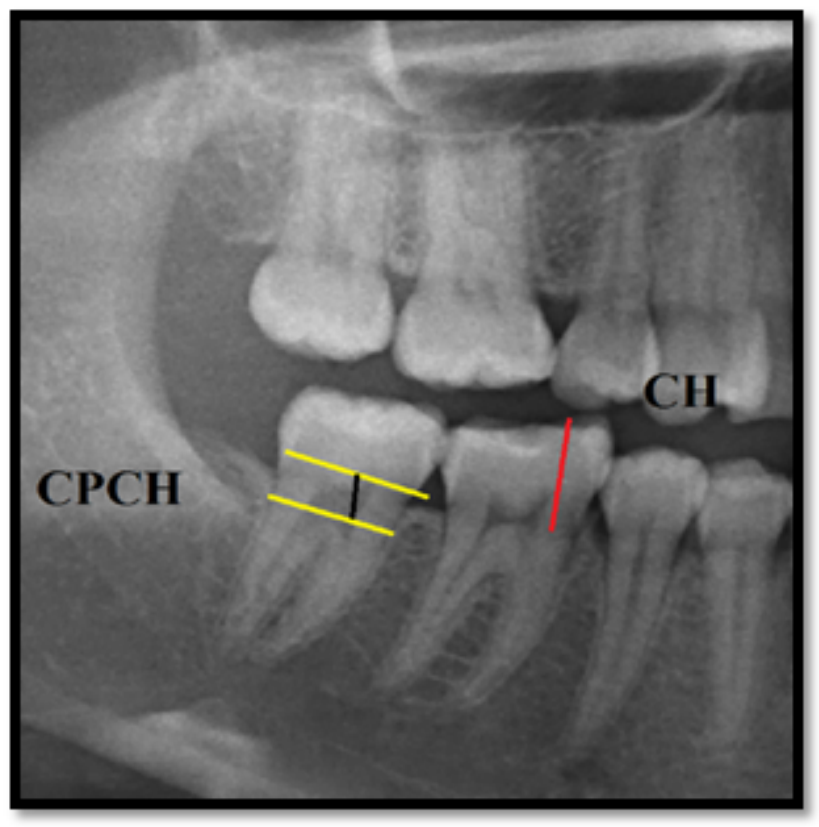

Fig. 5: Panoramic Image showing measurements on right mandibular first molar. To calculate Tooth Coronal Index, Coronal Height $(\mathrm{CH})$ was measured vertically straight from the cervical line to the tip of the highest cusp [represented by Red Line]. Coronal Pulp Cavity Height $(\mathrm{CPCH})$ was measured vertically from the cervical line [Red Line] to the tip of the highest pulp horn [Yellow Line].

calculated according to specific equations developed, This method require complicated calculations not give reliable results. ${ }^{16}$

In present study we used modified method of Kvaal's et al. in 2011. He concluded that better accuracy in age prediction were obtained subjects based on linear measurements of pulp. The present study was done to develop an independent procedure to estimate age using digital radiographs of multirooted posterior teeth with acceptable margins for forensic age prediction $(10 \pm$ years). We have used a new procedure where in the height of the pulp chamber and height of the crown root trunk was measured and ratio; PCTHR was calculated. PCTHR was correlated with chronological age of the study subjects with a positive correlation $(\mathrm{r}=0.48 ; \mathrm{P}=0.001)$. Regression equation derived from PCTHR ratio were used to estimate the age difference between actual age and calculated age was found to be statistically non significant $(\mathrm{P}=0.853)$. The MAE in our study was 7.51 years which was under the acceptable error limits in forensic age estimation.

The mesiodistal diameter of the posterior teeth is larger for males than females. ${ }^{17}$ Dentin was significantly thicker in males than females, and is $3.5-4.0 \mathrm{~mm}$ thicker in molars, which accounts for the dimorphism in the mesiodistal diameter. Enamel thickness which is $0.4-0.7 \mathrm{~mm}$ greater

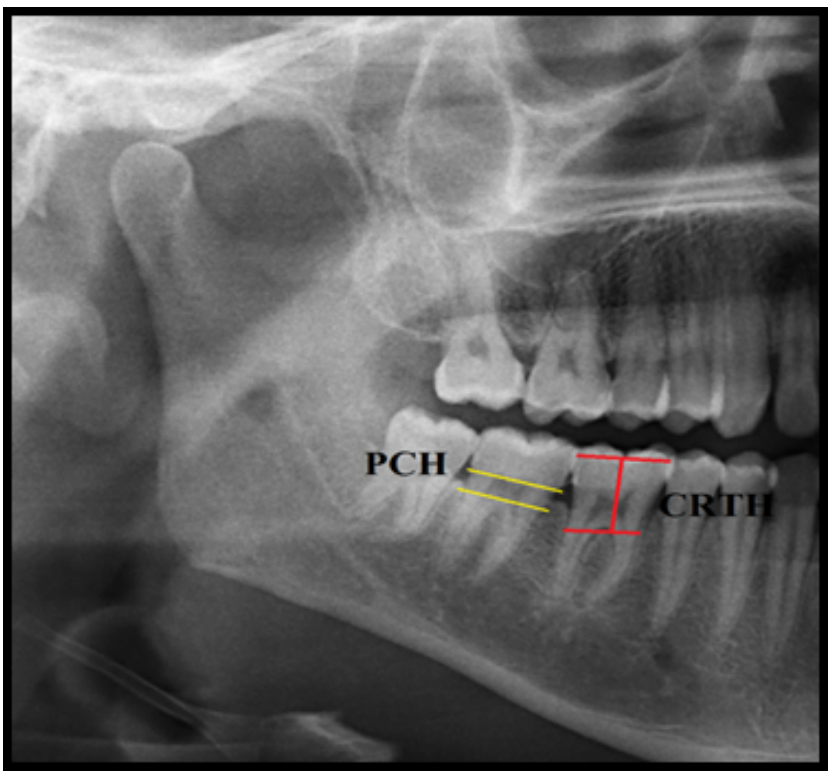

Fig. 6: Panoramic Image showing measurements on right mandibular first molar. To calculate Pulp Chamber Crown Root Trunk Height (PCTHR), Crown Root Trunk Height (CRTH)[vertical red line] was calculated by measurement of distance between the central fossa and the highest point on root furcation [represented by red lines]. Pulp chamber Height (PCH) was calculated which is the distance between the roof and floor of the pulp of the pulp chamber in the same axis [represented by yellow lines]

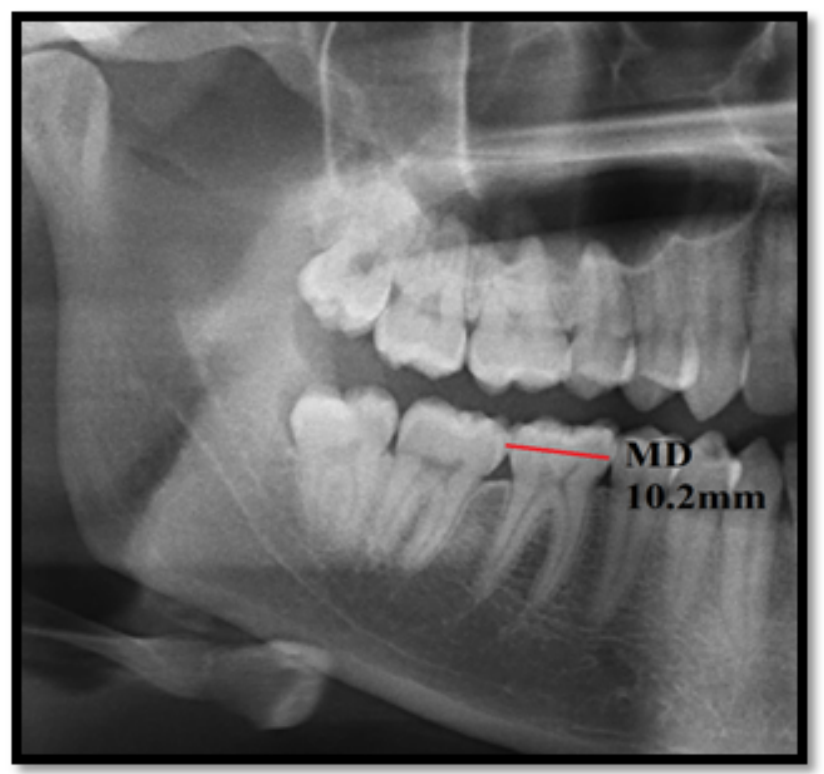

Fig. 7: Panoramic Image showing measurements on right mandibular first molar. To calculate Bicervical diameter in mesiodistal direction(MD) was measured by a line drawn from contact point in mesial and distal aspect of lower right mandibular molar. [represented by red lines] 
for the molars than premolars shows no significant sex differences. Alvesalo et suggested that the Y chromosome increases the mitotic potential of developing tooth germs and promotes dentin growth. Amelogenesis, on the other hand, appears to be promoted by the $\mathrm{X}$ chromosomes. ${ }^{18}$ According to Stroud sexual dimorphism in Mesiodistal tooth sizes is due to differences in dentin thickness not enamel thickness. ${ }^{5}$ Present study sample showed that Mesiodistal dimension of posterior teeth is larger in males than in females. Mean standard deviation of Mesiodistal dimension in males $(11.98 \pm 1.33)$ more than females (10.20土1.16).

The length of the coronal pulp cavity shows a significant correlation with chronological age Calculated as TCI. The reduction in the size of the pulp cavity resulting from a deposition of secondary dentine with aging can be assessed by radiographs. ${ }^{11}$ Assessment of the pulp/tooth index is an indirect quantification of secondary dentin deposition. ${ }^{19}$ Various studies were conducted on periapical and panaromic radiographs using TCI and its correlation with age. Kvaal et al. had established significant correlation between TCI for molars.

The results obtained in the present study prove that there is a positive correlation with age i.e. as the age advances TCI increases. ${ }^{12}$ Prapanpoch et al. found no significant correlation between the age of an individual and the width and height of the pulp chamber evaluated on dental radiographs, and suggested that these measurements should not be used as a reliable method of age determination. ${ }^{20}$ Igbigbi and Nyirenda mentioned that due to influence of estrogen on the formation of secondary dentin, gender has a significant influence on age estimation using TCI. ${ }^{21}$ The results of present study show significant gender differences inTCI.TCI of males is larger than females. This was in favour of the study by Shrestha in 2014 shows TCI is higher in males than in females. ${ }^{3}$

\section{Conclusion}

TCI and PCTHR are simple non destructive, cost effective methods for morphometric analysis of reduction in size of pulpal cavity with individual's age. This modified kvaal's method can be used for forensic determination of age using digital OPG. From the results of study it could be concluded that chronological age has positive correlation with both TCI \& PCTHR. Mandibular first molar was found to be most reliable marker to determine age. Mesiodistal dimension of molar is greater in males than females also have been proved.

\section{Source of Funding}

None.

\section{Conflict of Interest}

None.

\section{References}

1. Gotmare SS, Shah T, Periera T, Waghmare MS, Shetty S, Sonawane S. The coronal pulp cavity index: A forensic tool for age determination in adults. Dent Res $J$. 2019;16(3):160-5.

2. Morsi DAE, HM HMR, Aziza A, El-Sherbiny M. Tooth Coronal Pulp Index as a Tool for Age Estimation in Egyptian Population. J Forensic Sci Criminol. 2015;3:201.

3. Shrestha M. Comparative evalaluation of two established age estimation techniques (Two histological and radiological) by image analysis software using single tooth. J Forensic Res. 2014;5:1-6.

4. Mittal S, Nagendrareddy SG, Sharma ML, Agnihotri P, Chaudhary S, Dhillon M. Age estimation based on Kvaal's technique using digital panoramic radiographs. J Forensic Dent Sci. 2016;8(2):115.

5. Stroud JL, Buschang PH, Goaz PW. Sexual dimorphism in mesiodistal dentin and enamel thickness. Dentomaxillofac Radiol. 1994;23(3):169-71.

6. Gopinathan PA, Monalisa W, Kokila G, Sharma HD, Singh OM, Kumaraswamy S. Sexual dimorphism of enamel area, coronal dentin area, bicervical diameter and dentinoenamel junction scallop area in longitudinal ground section. J Oral Maxillofac Pathol. 2018;22(3):423-9.

7. Moss ML, Chase PS, Howes RI. Comparative odontometry of the permanent post-canine dentition of American Whites and Negroes. Am J Physical Anthropol. 1967;27(2):125-42.

8. Ikeda N, Umetsu K, Kashimura S, Suzuki T, Oumi M. Estimation of age from teeth with their soft X\&\#8209;ray finding. Nihon Hoigaku Zasshi. 1985;39:244-50.

9. Stavrianos CH, Mastagas D, Stavrianou I, Karaiskou O. Dental age estimation of adults: A review of methods and principles. Res $J$ Med Sci. 2008;2:258-68.

10. Gustafson G. Age determination from teeth. J Am Dent Assoc. 1950;41:45-54.

11. Veera SD, Kannabiran J, Suratkal N, Chidananada DB, Gujjar KR, Goli S. Coronal pulp biomarker: A lesser known age estimation modality. J Indian Acad Oral Med Radiol. 2014;26(4):398-404.

12. Bosmans N, Ann P, Aly M, Willems G. The application of Kvaal's dental age calculation technique on panoramic dental radiographs. Forensic Sci Int. 2005;153(2-3):208-12.

13. Kvaal SI, Kolltveit KM, Thomsen IO, Solheim T. Age estimation of adults from dental radiographs. Forensic Sci Int. 1995;74(3):175-85.

14. Landa MI, Garamendi PM, Botella MC, Alemán I. Application of the method of Kvaal et al. to digital orthopantomograms. Int J Legal Med. 2009;123(2):123-8.

15. Drusini AG, Toso O, Ranzato C. The coronal pulp cavity index: A biomarker for age determination in human adults. Am J Physical Anthropol. 1997;103(3):353-63.

16. Paewinsky E, Pfeiffer H, Brinkmann B. Quantification of secondary dentine formation from orthopantomograms? a contribution to forensic age estimation methods in adults. Int $J$ Legal Med. 2005;119(1):27-30.

17. Garn SM, Lewis AB, Swindler DR, Kerewsky RS. Genetic Control of Sexual Dimorphism in Tooth Size. J Dent Res. 1967;46(5):963-72.

18. Alvesalo L, Tammisalo E, Townsend G. Upper Central Incisor and Canine Tooth Crown Size in 47,XXY Males. J Dent Res. 1991;70(7):1057-60.

19. Grover S, Marya CM, Avinash J, Pruthi N. Estimation of dental age aand its comparision with chronological age:Accuracy of two radiographic methods. Med Sci Law. 2013;52:32-5.

20. Prapanpoch S, Dove SB, Cottone JA. Morphometric Analysis of the Dental Pulp Chamber as a Method of Age Determination in Humans. Am J Forensic Med Pathol. 1992;13(1):50-5.

21. Igbigbi PS, Nyirenda SK. Age estimation of Malawian adults from dental radiographs. West Afr J Med. 2006;24(4):329-33. 


\section{Author biography}

Jyoti Sukhwani PG Student

Abhijeet Deoghare Professor and HOD

Chinar Fating Reader

Satyendra Kumar Jha Reader
Rohit Biranjan Senior Lecturer

Cite this article: Sukhwani J, Deoghare A, Fating C, Jha SK, Biranjan

R. Evaluation of tooth coronal index bicervical diameter in mesiodistal direction \& modified kvaals method for age and gender determination using digital panoramic radiographs: A retrospective study. IP Int J Maxillofac Imaging 2020;6(3):71-78. 